\title{
Effect of Dopants on the Sintering Behaviour and Stability of Tetragonal Zirconia Ceramics
}

\author{
G. S. A. M. Theunissen, A. J. A. Winnubst* \& A. J. Burggraaf \\ University of Twente, Faculty of Chemical Technology, Laboratory for Inorganic Chemistry, \\ Materials Science and Catalysis, PO Box 217,7500 AE Enschede, The Netherlands
}

(Received 3 May 1991: revised version received and accepted 22 August 1991)

\begin{abstract}
The microstructure development during non-isothermal and isothermal sintering has been studied for tetragonal zirconia ceramics $(T Z P)$ containing carious amounts of $Y, \mathrm{Ce}$ and Ti. Smaller grain sizes were obtained when Ce-TZP was doped with yttrium. This could be attributed to segregation of ytrium to the grain boundaries, thus causing an impurity drag. With increasing temperature the grain growth in the Ce-TZP samples became faster, which could be attributed to the absence of a dragging force. The slow. grain growth at low temperature in the Ce-TZP samples could be attributed to the slow diffusion kinetics of the diffusing species (trivalent and tetratalent cerium). The critical grain size for retainment of the tetragonal phase at room temperature is larger in the Y,Ce-TZP systems compared to the $Y-T Z P$ and $C e-T Z P$ systems. The chemical stability increased by doping $Y-T Z P$ with cerium or titanium.
\end{abstract}

Es wurde die Gefügeentwicklung von tetragonalen Zirkonoxid-Keramiken (TZP) mit verschiedenen Gehalten an $Y, C e$ und Ti während nicht isothermer und während isothermer Sinterung untersucht. Durch den Zusatz von Ytrium werden bei Ce-TZP-Keramiken geringere Korngrößen erzielt. Dieser Effekt könnte der Segregation von Yttrium zu den Korngrenzen zugeschrieben werden und resultiert darin, daß die Korngrenzen an Verunreinigungen festgehalten werden (impurity drag). Mit zunehmender Temperatur wurde das Kornwachstum in Ce-TZP-Proben beschleunigt, was mit dem Fehlen der zurücktreibenden Kraft zusammenhängen könnte. Das langsame Kornwachstum in Ce-TZP-Proben bei geringen Tempera-

* To whom correspondence should be addressed. turen könnte der langsamen Diffusionskinetik der diffundierenden Spezies (dreivertiges und vierwertiges $(e r)$ zugeschriehen werden. Die kritische Korngrößse für die Erhaltung der tetragonalen Phase bei Raumtemperatur ist größser für Y,Ce-TZPSysteme als für Y-TZP- und Ce-TZP-Systeme. Die chemische Stabilität nimmt mit dem Zusatz von Cer oder Titan $=u \quad Y-T Z P=u$.

On a étudié le développement de la microstructure pour des céramiques de zircone tétragonale (TZP), à diterses teneurs en $Y$, Ce et Ti. Les plus petites tailles de grain sont ohtenues quand la Ce-TZP est dopée à lyttrium. Ce résultat peut être expliqué par la ségrégation de l'ytrium aux joints de grain, constituant ainsi un piège à impuretés. A température croissante, la croissance de grain s'accélère dans les échantillons de Ce-TZP, phénomène attribuable à l'absence d'une force de drainage. A hasse température, la croissance de grain dans les échantillons de Ce$T Z P$ est lente, ce qui peut sexpliquer par la lenteur des cinétiques de diffusion des espèces diffusantes (cérium trivalent et tétratalent). La taille de grain critique pour conserver la phase tétragonale à température anbiante est plas importante dans les systemes Y.Ce$T Z P$ que dans les systemes $Y-T Z P$ et Ce-TZP. On augmente la stabilité chimique par dopage de $Y-T Z P$ par le cérium et le titane.

\section{Introduction}

Polycrystalline $100 \%$ tetragonal $\mathrm{ZrO}_{2}-\mathrm{Y}_{2} \mathrm{O}_{3}$ ceramics (Y-TZP) are regarded as materials exhibiting high strength and toughness. ${ }^{1}$ However, when exposed to humid atmospheres, the critical grain size needed to preserve the tetragonal phase is reduced drastically. ${ }^{2.3}$ In the case of a $3 \mathrm{~mol} \% \mathrm{Y}_{2} \mathrm{O}_{3}-\mathrm{ZrO}_{2}$

Journal of the European Ceramic Society 0955-2219/92/\$05.00 @ 1992 Elsevier Science Publishers Ltd, England. Printed in Great Britain 
ceramic the grain size should be less than $0.3 \mu \mathrm{m}$ to preserve the tetragonal phase. ${ }^{2}$ Besides yttrium, a number of other stabilizing agents like $\mathrm{Ca}, \mathrm{Mg}, \mathrm{Ce}$ or $\mathrm{Ti}$ are used to stabilize the tetragonal phase to room temperature. Especially in the last few years increasing attention has been paid to ceria-doped tetragonal zirconia (Ce-TZP). A very high value for the fracture toughness $\left(35 \mathrm{MPa} \mathrm{m}{ }^{1 / 2}\right)$ has been reported for a Ce-TZP ceramic doped with 12 at. $\%$ Ce. ${ }^{4}$ This material also shows a good ageing behaviour (i.e. a stable tetragonal phase under chemical and thermal treatments). ${ }^{5}$ Besides this, $\mathrm{Ce}$ TZP shows very interesting plastic deformation behaviour. ${ }^{6}$ A disadvantage of Ce-TZP is the fact that higher temperatures and/or longer sintering times are needed for densification of the material. This results in a large grain size after sintering, which is a disadvantage for plastic deformation processes and for obtaining high strength. Finally, the strength of Ce-TZP materials is usually lower than that of $Y$ TZP.

It is possible to obtain a dense 6 at. $\%$ Y-TZP ceramic $(\rho>97 \%)$ with a very small grain size $(100 \mathrm{~nm}){ }^{7}$ During sintering of these ceramics yttrium segregates to the grain boundary. The yttriumenriched grain boundary is believed to inhibit grain growth by means of a drag mechanism. ${ }^{7.8}$ This small grain size is favourable for superplastic deformation of the ceramic. ${ }^{9,10}$ Materials formed in this way can be interesting for post-sintering heat treatments where the grain growth can be controlled very well. To guide such heat treatments a TTT diagram ${ }^{11.12}$ can be constructed.

It would be very favourable when good chemical stability $(\mathrm{Ce})$ can be combined with a small grain size $(\mathrm{Y})$ in the same ceramic material. Some work on Y,Ce-TZP shows an improved chemical stability compared to Y-TZP. ${ }^{13}$ A similar effect has been reported for Y,Ti-TZP ceramics. ${ }^{13}$ Duh et al. ${ }^{14}$ showed that doping of Ce-TZP with yttrium gives rise to smaller grain sizes. In studying the ceriadoped system it is important to note whether or not reduction of the cerium species occurs. When reduction takes place an extra phase is formed which destabilizes the tetragonal phase. ${ }^{15}$ According to Heussner \& Claussen ${ }^{15}$ this was mainly caused by a decrease in $\mathrm{CeO}_{2}$ content, which changed the composition to a concentration range where the monoclinic phase was stable at room temperature. Furthermore, reduction of $\mathrm{Ce}^{4+}$ might promote the nucleation of the cubic phase. ${ }^{16}$ Therefore some attention has to be paid to the presence of trivalent cerium.

In this paper the effects of $\mathrm{Y}, \mathrm{Ce}$ and $\mathrm{Ti}$ (with a total dopant concentration of 6-10at.\%) on the sintering behaviour and the thermal and chemical stability of tetragonal zirconia ceramics are studied.

\section{Experimental Procedure}

Zirconia ceramics with various yttrium, cerium and titanium concentrations have been synthesized (Table 1) by means of a gel-precipitation technique. This involves the hydrolysis of a diluted metal chloride solution ('chloride' method) in an excess of $25 \mathrm{wt} \%$ ammonia. ${ }^{17}$ During hydrolysis the $\mathrm{pH}$ was kept at a value of 11 or higher. After completion of the precipitation the gel was washed with a water/ ammonia mixture and ethanol in order to remove chlorides and water, respectively. After drying at $120^{\circ} \mathrm{C}$ the gel was calcined for $2 \mathrm{~h}$ at $550^{\circ} \mathrm{C}$. Powder compacts were isostatically pressed at $400 \mathrm{MPa}$. Details of the procedure are described elsewhere. ${ }^{17}$

TGA measurements were performed on dense and porous ceramics using a Setaram G70 thermal gravimetric analyser. More details concerning the instrumental set-up can be found in Ref. 18. During the TGA analysis the samples were subjected to a series of changes in temperature or atmosphere. The samples were first heated under a nitrogen atmosphere to about $1450 \mathrm{C}$ (step 1). The atmosphere was then changed from nitrogen to pure oxygen (step 2). After reaching constant weight the sample was cooled under nitrogen to room temperature (step 3). In step 4 the sample was heated to $1450^{\circ} \mathrm{C}$ (under $\mathrm{N}_{2}$ ) and subsequently the atmosphere was changed to air (step 5), held at that temperature until constant weight was obtained and cooled to room temperature (step 6). Heating and cooling rates were $2{ }^{\circ} \mathrm{C} /$ min. The flow rate of the gases used was in all cases $200 \mathrm{~cm}^{3} / \mathrm{min}$ at a pressure of $1050 \mathrm{mbar}$. The $p \mathrm{O}_{2}$ in the outlet gas stream was measured with a $\mathrm{ZrO}_{2}$ oxygen sensor.

Infrared (IR) measurements were performed in the $4000-400 \mathrm{~cm}^{-1}$ region on pressed discs of a

Table 1. Composition of the samples used in this study

\begin{tabular}{lcccc}
\hline Code & $\begin{array}{c}\mathrm{ZrO}_{2} \\
(\mathrm{~mol} \%)\end{array}$ & $\begin{array}{c}\mathrm{YO}_{1.5} \\
(\mathrm{~mol} \%)\end{array}$ & $\begin{array}{c}\mathrm{CeO}_{2} \\
(\mathrm{~mol} \%)\end{array}$ & $\begin{array}{c}\mathrm{TiO}_{2} \\
(\mathrm{~mol} \%)\end{array}$ \\
\hline ZY5.8 & $94 \cdot 2$ & $5 \cdot 8$ & & \\
ZCe6.8 & $93 \cdot 2$ & & $6 \cdot 8$ & \\
ZCe9 & 91 & & 9 & \\
ZCe12 & 88 & & 12 & \\
ZY4Ce2 & 94 & 4 & 2 & \\
ZY4Ce4 & 92 & 4 & 4 & \\
ZY6Ce2 & 92 & 6 & 2 & 5 \\
ZY5Ti5 & 90 & 5 & & 5 \\
\hline
\end{tabular}


$3 \mathrm{wt} \%$ powder mixture in $\mathrm{KBr}$ using a Nicolet 20SXB FTIR spectrometer system with a resolution of $2 \mathrm{~cm}^{-1}$.

The samples were sintered non-isothermally (with a heating rate of $2 \mathrm{C} / \mathrm{min}$ ) or isothermally at temperatures between 600 and $1400 \mathrm{C}$, either in a Vecstar tube furnace or in a Netzsch $402 \mathrm{E}$ dilatometer.

X-Ray fluorescence spectrometry, using a Philips PW1410 spectrometer, was used for the analysis of the overall composition. A Philips PW1370 X-ray diffractometer with $\mathrm{Cu} K_{x}$ radiation was used to determine the phase composition. The volume fraction of the monoclinic phase was estimated according to eqn (1): ${ }^{19}$

$$
V_{\mathrm{m}}=\frac{1 \cdot 311 X_{\mathrm{m}}}{1+0 \cdot 311 X_{\mathrm{m}}}
$$

where $V_{\mathrm{m}}$ is the volume fraction of the monoclinic phase and $X_{\mathrm{m}}$ the integrated intensity ratio, defined as

$$
X_{\mathrm{m}}=\frac{I(111)_{\mathrm{m}}+I(11 \overline{1})_{\mathrm{m}}}{I(111)_{\mathrm{m}}+I(11 \overline{1})_{\mathrm{m}}+I(111)_{\mathrm{t}}}
$$

with $I$ the peak intensity, and where the subscripts $m$ and $t$ represent the monoclinic and tetragonal phase, respectively.

Crystallite sizes in the region $<70 \mathrm{~nm}$ were determined by means of X-ray line broadening measurements (XRLB). A Jeol 200CT transmission electron microscope was used for direct observations of grain sizes in the region $<100 \mathrm{~nm}$. Grain sizes $>70 \mathrm{~nm}$ were calculated by the method of $\mathrm{Oel}^{20}$ from SEM pictures using a Hitachi S600 or a Jeol JSM-35CF scanning electron microscope.

Dense Ce-TZP ceramics $\left(\rho_{\text {re1 }}>95 \%\right)$ sintered between 1030 and $1200^{\circ} \mathrm{C}$ were used to study the stability of the tetragonal phase. The cooling part of dilatometer curves was used to determine the temperature where transformation from the tetragonal to the monoclinic started $(M$, temperature). In the dilatometer curves the $M_{\mathrm{s}}$ temperature is designated as the temperature where a sudden expansion of the sample was observed (Fig. 1). As will be shown in

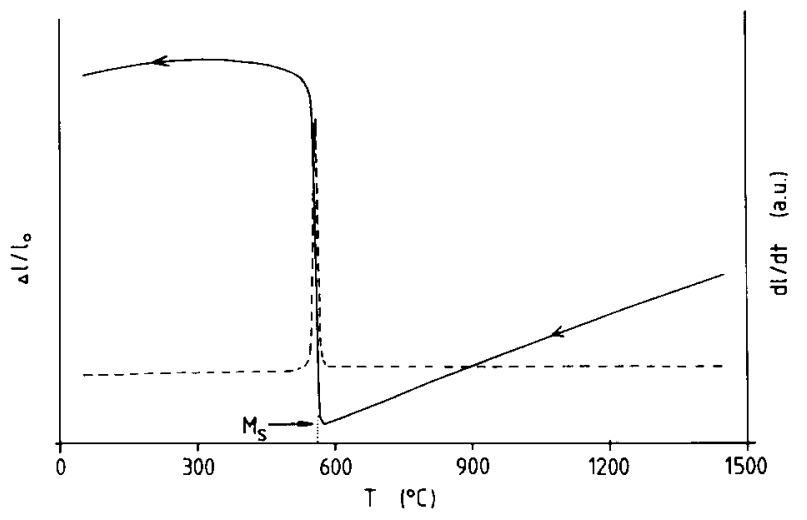

Fig. 1. Cooling part (cooling rate $2 \mathrm{C} / \mathrm{min}$ ) of a dilatometer curve obtained from a ZCe6.8 sample (grain size $10 \mu \mathrm{m}$ ). The sudden dimensional change $\left(\Delta / / I_{0}\right)$ indicates the transformation temperature $\left(M_{\mathrm{s}}\right) \cdot(-\cdots) \Delta / l_{0} ;(-\cdots) \mathrm{d} l / \mathrm{d} t$.

Section 3.7, the $M_{\mathrm{s}}$ temperature is a measure of the thermal stability.

The samples were chemically aged for $5 \mathrm{~h}$ in distilled $\mathrm{H}_{2} \mathrm{O}$ at $180 \mathrm{C}$ in an autoclave operating at a steam pressure of $20 \mathrm{bar}$.

\section{Results and Discussion}

\subsection{Powder characteristics}

The chloride synthesis resulted for the yttriumcontaining compositions in a powder with crystallite "chains" with a primary crystallite size of $8 \mathrm{~nm}$. These chains form very small cluster 'aggregates' (with a size of about $16 \mathrm{~nm}$ ) at the intersections of the chains and weak agglomerates which can be destroyed almost completely by isostatic pressing. ${ }^{17}$ More details concerning the microstructure of the chloride-derived powders can be found in Ref's 17 and 21 . In the Ce-TZP powders the primary crystallite size was slightly larger $(10 \mathrm{~nm}$, Table 2$)$. For both the Y-TZP and Y,Ce-TZP powders a BET surface of about $120 \mathrm{~m}^{2} / \mathrm{g}$ was measured. The BET surface of the Ce-TZP powders was about $90 \mathrm{~m}^{2} / \mathrm{g}$. Particle sizes are also calculated according to eqn (3):

$$
d_{\mathrm{BET}}=\frac{6}{\rho S_{\mathrm{BET}}}
$$

with $\rho$ the theoretical density and $d_{\mathrm{BLT}}$ the crystallite size obtained from the equivalent BET surface. For

\begin{tabular}{|c|c|c|c|c|c|c|}
\hline Temperature ( $C)$ & $Z Y 5 \cdot 8$ & $Z Y 4 C e 2$ & $2 Y 4 C e^{4}$ & $7 Y 6 C^{2} 2$ & $\left.Z C e^{9}\right)$ & ZY5Ti5 \\
\hline After calcination & 8 & 8 & 8 & 8 & 10 & 8 \\
\hline 900 & 19 & $17^{a}$ & $16^{\prime \prime}$ & $17^{a}$ & $16^{\prime \prime}$ & \\
\hline 1050 & 38 & $31^{4}$ & $33^{\prime \prime}$ & $31^{4}$ & $31^{a}$ & \\
\hline
\end{tabular}

Table 2. Grain sizes (in $\mathrm{nm}$ ) of doped zirconia materials after non-isothermal sintering with a heating rate of $2 \mathrm{C} / \mathrm{min}$

${ }^{a}$ After Boutz et $a l .22$ 
Ce-TZP $d_{\text {BET }}$ is about $11 \mathrm{~nm}$. This is in good agreement with the crystallite size as determined from the XRLB measurements. Therefore the crystallite size and surface area are within $25 \%$ of values obtained from Y-TZP powders prepared by this route.

\subsection{Compaction behaviour}

The compaction behaviour of the Y,Ce-TZP powders is similar to the compaction behaviour of the $\mathrm{Y}$ TZP powders. ${ }^{17}$ The compaction curve of the CeTZP powder is somewhat different from the compaction curve of the Y-TZP powder (Fig. 2). The yield point $P_{y}$ (intersection of the two linear parts) seems to be somewhat lower for the Ce-TZP powders (about $50 \mathrm{MPa}$ ) compared with the other powders. The yield density $\rho_{y}(25-26 \%)$ is somewhat higher. The compaction curve of the Y,Ti-TZP powder is completely different from the previous compaction curves (Fig. 2). In this curve only one straight line is observed starting from a compaction pressure $P=30 \mathrm{MPa}$. This indicates that the agglomerates present are very weak. ${ }^{17}$ Below 30 MPa no intact samples could be obtained. After compaction at $400 \mathrm{MPa}$ the same relative density as for all the other powders is obtained.

\subsection{Oxidation state of the cerium species}

\subsubsection{Thermogravimetric analysis (TGA)}

At elevated temperatures reduction of tetravalent cerium to trivalent cerium can occur. This can be represented by eqn (4):

$$
2 \mathrm{Ce}_{\mathrm{Zr}_{\mathrm{r}}} \rightarrow 2 \mathrm{Ce}_{\mathrm{Zr}_{\mathrm{r}}}^{\prime}+\mathrm{V}_{\mathrm{O}}^{*}+\frac{1}{2} \mathrm{O}_{2}
$$

In the case where all cerium present changes its oxidation state a weight loss of 0.57 and $0.74 \mathrm{wt} \%$ can be expected for ZCe9 and ZCe12 samples, respectively.

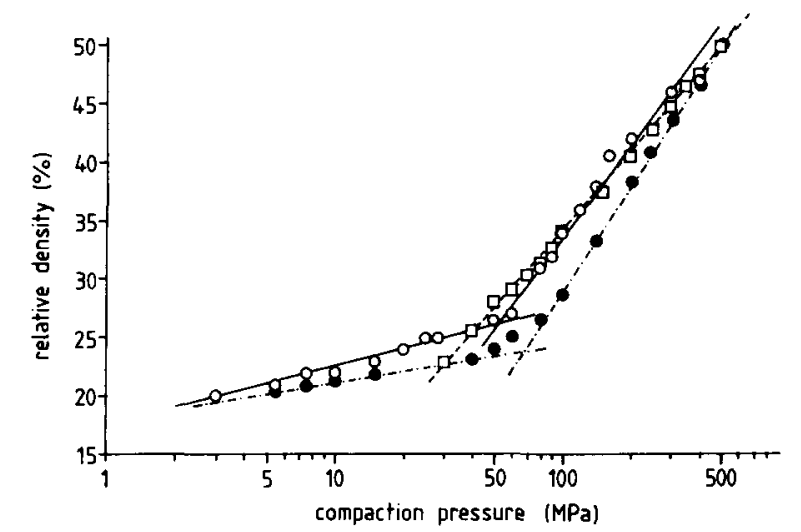

Fig. 2. Typical compaction curves for (-...) Y-TZP, $\left(-\mathrm{O}-\mathrm{Ce}\right.$-TZP and $\left(--\square^{--}\right)$Y,Ti-TZP compacts.
In Fig. 3 weight-time, temperature-time and $p \mathrm{O}_{2}$-time curves are shown for a $\mathrm{ZCe} 12$ sample (a similar curve has been obtained for a ZCe9 sample).

In step 1 the (porous) sample is heated to about $1450^{\circ} \mathrm{C}$. A gradual decrease in weight is observed which is mainly attributed to removal of adsorbed gases. At about $1150^{\circ} \mathrm{C}$ (when the sample is $85-90 \%$ dense) the $\mathrm{pO}_{2}$ suddenly increases, indicating loss of oxygen. Presumably the reduction reaction becomes significant at this temperature. At $1450^{\circ} \mathrm{C}$ (the sample is now $95 \%$ dense) the atmosphere is switched to pure oxygen. This leads to a weight increase of about $0.2 \mathrm{wt} \%$. Assuming that this weight increase is only due to reoxidation of all trivalent cerium species, about $27 \%$ of the cerium present has been reduced during the heating process (step 1). The observation that the weight decrease of the porous sample in step 1, when going from 1150 to $1450 \mathrm{C}$ (region of increasing $p \mathrm{O}_{2}$ ), is much smaller than the weight increase during oxidation (step 2) indicates that the reduction step in the porous sample already started at a temperature lower than $1150 \mathrm{C}$. This was supported by XPS measurements on porous $\mathrm{ZCe} 9$ samples where a considerable fraction of trivalent cerium was found on the surface after non-isothermal sintering to $1000^{\circ} \mathrm{C}$ (Table 3). In step 3 the atmosphere is changed to nitrogen again and the sample is cooled to room temperature. This causes some reduction of the cerium species (and thus some weight loss). After this an increase and a decrease in weight are observed during cooling and heating, respectively (steps 3 and 4). A similar weight profile has been observed (in steps 3 and 4) when running the same program without a sample. Therefore this section of the observed profile can be attributed to an apparatus effect. In step 4 (heating under $\mathrm{N}_{2}$ ) the increase in $p \mathrm{O}_{2}$ is now observed between $1200-1250^{\circ} \mathrm{C}$. When switching over to air (step 5) the observed weight increase is much smaller than before, 0.045 and $0.065 \mathrm{wt} \%$ for ZCe9 and ZCe12 samples, respectively. Hence $7.7 \%$ and $8.6 \%$ of the total amount of cerium present changed its oxidation state. The question, however, remains whether all the reduced cerium was reoxidized again

Table 3. Segregation data obtained from surfaces of ZCe 9 measured by XPS ${ }^{21}$

\begin{tabular}{ccc}
\hline $\begin{array}{c}\text { Temperature } \\
(C)\end{array}$ & $\begin{array}{c}\text { Surface composition } \\
(\text { ZCey) }\end{array}$ & Fraction $\mathrm{Ce}^{3+}$ \\
\hline 1000 & ZCe9 & $0 \cdot 38$ \\
1200 & ZCe10 & $0 \cdot 46$ \\
1300 & ZCe14 & 0.49 \\
1400 & ZCe22 & $0 \cdot 51$ \\
\hline
\end{tabular}




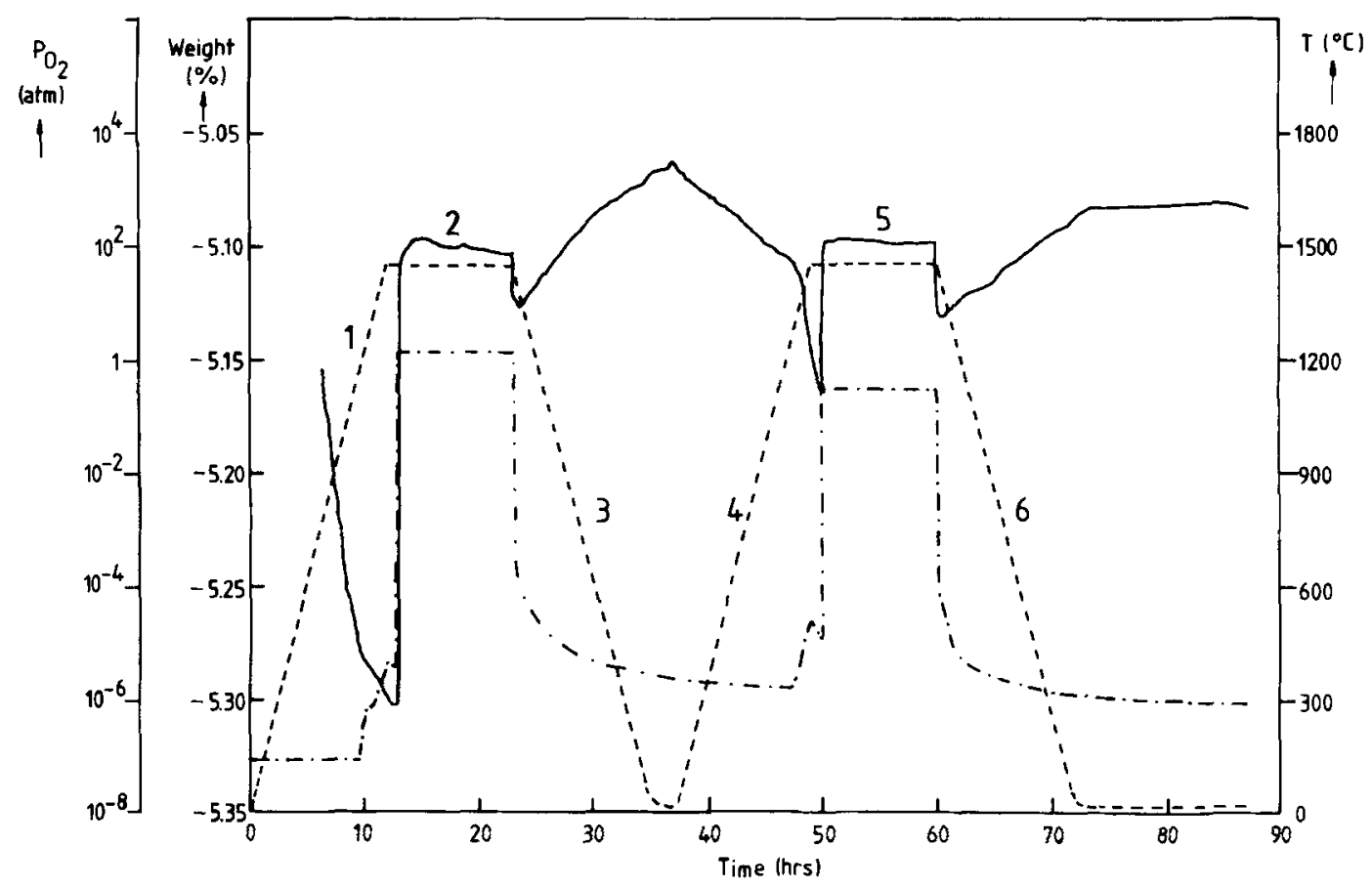

Fig. 3. TGA curves of ZCe12. (-) Weight-time: $(---)$ temperature-time; $(-\cdots-) \log p \mathrm{O}_{2}-$ time. The numbers denote the various steps (Section 2).

in step 2. If this is not the case, the real percentage of trivalent cerium will be higher than the calculated amounts. The observation that the weight decrease during heating (the last stage of step 4) was comparable to the weight increase during oxidation (step 5) indicates that in dense Ce-TZP the reduction reaction becomes significant above $1200^{\circ} \mathrm{C}$.

The observation that more cerium was reduced in the porous sample (step 1) than in the dense sample (step 4) is in agreement with the observation of Heussner \& Claussen. ${ }^{15}$ They reasoned that because the depth of the reduced layer is controlled by the diffusion of oxygen from the bulk to the surface, pores accelerate the oxygen diffusion in the bulk and, hence, more $\mathrm{CeO}_{2}$ is reduced in porous material. In $\mathrm{ZrO}_{2}-14 \mathrm{~mol}_{0} \% \mathrm{CeO}_{2}$ the depth of the reduced layer was estimated to be $130 \mu \mathrm{m}$ at a temperature of $1400 \mathrm{C} .{ }^{15}$ Hernandez et $a l .{ }^{16}$ showed with diffuse reflectance spectroscopy that reduction of the cerium species occurred in systems with a ceria concentration higher than $6 \mathrm{~mol} \%$. So the reduction seemed to be more pronounced with increasing ceria content. Meriani ${ }^{23}$ studied the redox behaviour of (porous) ZCe 50 samples under reducing conditions $\left(\mathrm{Ar}+5\right.$ vol. $\left.\% \mathrm{H}_{2}\right)$. No density was mentioned. The redox reaction was found to begin already at $300^{\circ} \mathrm{C}$. At $1100 \mathrm{C}$ about $75 \%$ of the cerium was reduced. Complete reduction was obtained after a hightemperature isothermal step (no temperature and time mentioned).

\subsubsection{Infrared (IR) studies}

In Fig. 4 three standard spectra are shown. The characteristics of the spectra are summarized in Table 4. Spectrum 1 is obtained from a ZCe9 sample sintered under vacuum at $1400^{\circ} \mathrm{C}$ for $2 \mathrm{~h}$ and subsequently quenched to room temperature. The reduction of this sample was indicated by the greenblue colour, in contrast to the green-yellow colour usually found. Spectrum 2 is taken from a ZCe9 powder which was heat treated at $1000^{\circ} \mathrm{C}$ and which consists mainly of the monoclinic phase. Due to the heat treatment a small fraction of trivalent cerium might be present. Finally, spectrum 3 is taken from a calcined ZCe9 powder which consists mainly of the tetragonal phase. In spectra 2 and 3 clear $\mathrm{H}_{2} \mathrm{O}$ bands are seen at 3400 and $1630 \mathrm{~cm}^{-1}$. The small band at $\sim 2400 \mathrm{~cm}^{-1}$ (spectrum 3) can be attributed to adsorption of $\mathrm{CO}_{2}$. Further bands are seen at 1337 . 1130 and $1110 \mathrm{~cm}^{-1}$. These bands are not very interesting because they are mainly due to adsorbed molecules and are not structural bands (the energy is not high enough). In the tetragonal sample a series of small bands is seen between 400 and $500 \mathrm{~cm}^{-1}$. IR spectra of tetragonal ZY 5.8 samples have been made by Philipi \& Mazdiyasni. ${ }^{24}$ In these spectra a series of bands between 400 and $500 \mathrm{~cm}^{-1}$ has also been found. Although the positions of the bands in the Ce-TZP sample might be shifted slightly, it can be expected that these bands are characteristic for the tetragonal structure. Philipi and Mazdiyasni also 


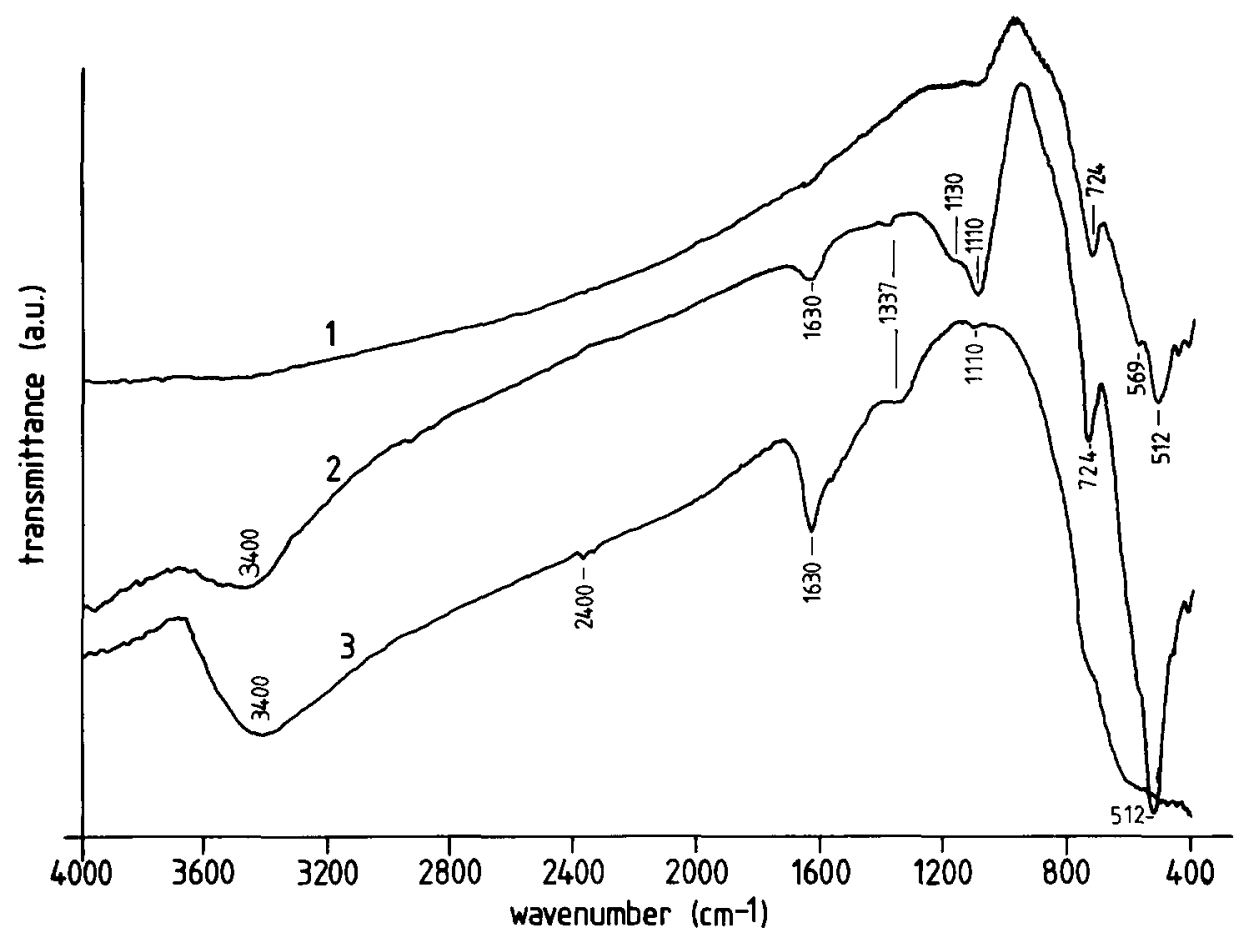

Fig. 4. IR spectra of ZCe9 samples as detailed in Table 4: 1, trivalent cerium, monoclinic structure; 2 , tetravalent cerium, monoclinic structure; 3 , tetravalent cerium, tetragonal structure.

Table 4. Summary of characteristics of ZCe9 samples used for IR studies

\begin{tabular}{|c|c|c|c|}
\hline \multirow[t]{2}{*}{ Spectrum } & \multirow[t]{2}{*}{ Heat treatment } & \multicolumn{2}{|c|}{ Characteristic } \\
\hline & & Crystal structure ${ }^{a}$ & Oxidation state ${ }^{b}$ \\
\hline 1 & Sintered at $1400 \mathrm{C}$ under vacuum for $2 \mathrm{~h}$ & Monoclinic & Mainly $3+$ \\
\hline 2 & Powder, heat treated at $1000 \mathrm{C}$ & Monoclinic & Mainly $4+$ \\
\hline 3 & As calcined & Tetragonal & $4+$ \\
\hline 4 & Sintered at $1400 \mathrm{C}$ in air for $2 \mathrm{~h}$ & Monoclinic/tetragonal & $\begin{array}{l}\text { Small but significant } \\
\text { fraction } 3+\end{array}$ \\
\hline
\end{tabular}

"Determined by XRD.

${ }^{h}$ Expected oxidation state of the Ce species.

reported bands at 740 and $510 \mathrm{~cm}^{-1}$ which are characteristic for the monoclinic structure. The 510 $\mathrm{cm}^{-1}$ band is also found in the present monoclinic samples (spectra 1 and 2), but the $740 \mathrm{~cm}^{-1}$ band seems to be shifted to $724 \mathrm{~cm}^{-1}$ in the Ce-TZP samples. In the reduced sample (spectrum 1) a small extra band has appeared at $569 \mathrm{~cm}^{-1}$, which does not seem to be present in the other two spectra. This strongly suggests that the $569 \mathrm{~cm}^{-1}$ band may be attributed to the presence of trivalent cerium.

In Fig. 5 the IR spectrum of a ZCe9 sample sintered at $1400^{\circ} \mathrm{C}$ in air for $2 \mathrm{~h}$ is shown (spectrum 4). For comparison the reference spectra from Fig. 4 of the reduced (spectrum 1) and the unreduced tetragonal (spectrum 3) samples are also shown. Spectrum 4 strongly resembles the spectrum of the reduced sample (spectrum 1). Only the bands are less intense. However, the presence of a weak band at
$569 \mathrm{~cm}^{-1}$, which is attributed to the presence of $\mathrm{Ce}^{3+}$, is again important. Therefore it can be concluded that trivalent cerium is present in the assintered sample (spectrum 4).

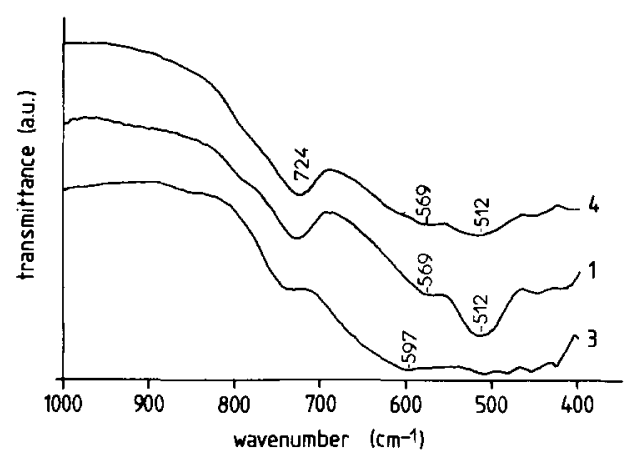

Fig. 5. Detailed IR spectra of ZCe9 samples as denoted in Table 4: 1 , trivalent cerium, monoclinic structure; 3 , tetravalent cerium, tetragonal structure; 4 , sintered at $1400 \mathrm{C}$ in air for $2 \mathrm{~h}$. 
Table 5. Oxidation state of the cerium species during nonisothermal sintering of Ce-TZP

\begin{tabular}{cl}
$\begin{array}{c}\text { Temperature } \\
(C)\end{array}$ & \multicolumn{1}{c}{ Characteristic } \\
$\begin{array}{c}\text { Porous sample } \\
<800-900 \\
800-1150\end{array}$ & $\begin{array}{l}\text { Main tetravalent } \\
\text { Tetravalent and trivalent. The trivalent } \\
\text { species is mainly situated in the external } \\
\text { surface area }\end{array}$ \\
$>1150$ & $\begin{array}{l}\text { Tetravalent and } \pm 30 \% \text { trivalent } \\
\text { Dense sample } \\
<800\end{array}$ \\
$800 \cdot 1200$ & $\begin{array}{l}\text { Mainly tetravalent } \\
\text { Tetravalent and trivalent. The trivalent } \\
\text { species is mainly situated in the external } \\
\text { surface area }\end{array}$ \\
$>1200$ & $\begin{array}{l}\text { Tetravalent and } \pm 10 \% \text { trivalent. The } \\
\text { trivalent species is maximal at the } \\
\text { external surface and decreases with } \\
\text { increasing distance from the external } \\
\text { surface }\end{array}$ \\
\hline
\end{tabular}

Considering the results discussed, the oxidation states listed in Table 5 are proposed for porous and dense Ce-TZP samples during non-isothermal sintering.

\subsection{Densification behaviour}

The dilatometer curves for a Y-TZP and Ce-TZP (ZCe6.8, ZCe9) compact are shown in Fig. 6, where the relative shrinkage $\left(\Delta / / I_{0}\right)$ is plotted as a function of the sintering temperature. The curves of the $\mathrm{Y}, \mathrm{Ce}-$ TZP and Y,Ti-TZP compacts are similar to the curve of the Y-TZP compact, but differ in the following respects. In the Y-TZP compact significant macroscopic densification starts close at $900 \mathrm{C}$, while this occurs at a somewhat higher temperature for the CeTZP compact. At about $1200^{\circ} \mathrm{C}$ the densification of Ce-TZP stops, although the relative density is only $90-92 \%$. No further densification is obtained with increasing temperature. Despite the somewhat lower densification rate nearly full density is obtained for

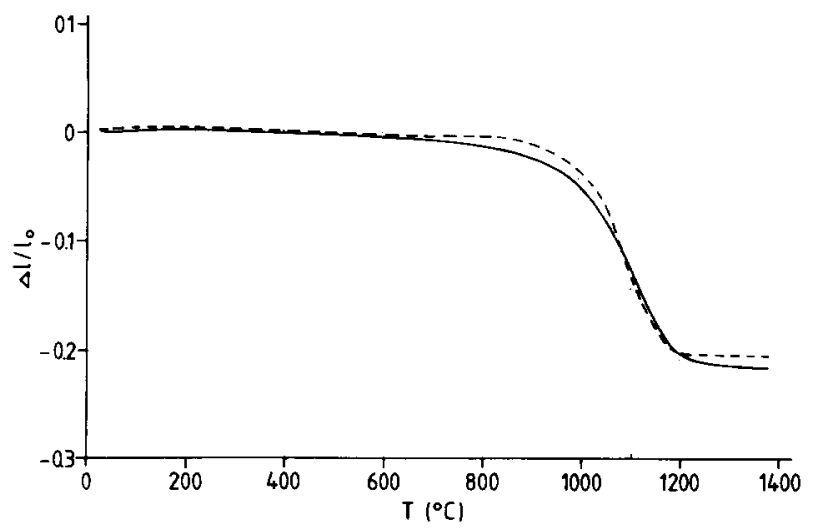

Fig. 6. Dilatometer curves of (-_-) Y-TZP and $(---)$ Ce-TZP sintered non-isothermally with a heating rate of $2 \mathrm{C} / \mathrm{min}$. the Y-TZP compact at temperatures just over $1200^{\circ} \mathrm{C}$.

This difference in densification behaviour between Y-TZP and Ce-TZP can probably be attributed to a difference in grain size at higher temperatures. Above $1200^{\circ} \mathrm{C}$ rapid grain growth is observed in the Ce-TZP compacts (Section 3.5), which strongly reduces the driving force for densification.

Preliminary dilatometer results obtained from ZCe12 compacts indicate that the densification in these compacts resembles more the densification behaviour in the Y-TZP compacts than the densification behaviour in the ZCe $6 \cdot 8$ and $\mathrm{ZCe} 9$ compacts. The reason for this behaviour is not yet clear.

The pore size evolution between 500 and $900^{\circ} \mathrm{C}$ is rather similar for all compacts. More details can be found in Refs 7 and 22.

It has become clear that during non-isothermal sintering up to $1400 \mathrm{C}$ no dense ZCe6.8 and ZCe9 compacts can be obtained. Although dense Y,CeTZP and Y,Ti-TZP compacts were obtained, nonisothermal sintering usually involves higher sintering temperatures and thus gives rise to coarsergrained materials. This is not in accordance with the present aims. Therefore attempts were made to densify the samples at lower temperature during isothermal sintering experiments.

Isothermal sintering results for a ZY 5.8 sample are shown in Ref. 7. In general, when using small samples (i.e. 2-3 g), similar results are obtained with the ternary Y,Ce-TZP and Y,Ti-TZP systems as for the Y-TZP sample. Therefore these results will not be discussed. The results did not reproduce very well when using larger samples (i.e. samples were not always dense after sintering at $1050 \mathrm{C}$ ). As for YTZP this is probably caused by the bad powder flowability.

Some isothermal sintering results on Ce-TZP samples are presented in Table 6 . No high densities nor large percentages of tetragonal phase were obtained in the ZCe6.8 samples despite the small grain sizes. Using relatively low sintering temperatures, rather high percentages of the tetragonal phase could be obtained in the ZCe9 samples. As expected, the percentage of tetragonal phase decreases with increasing grain size. Dense and fully tetragonal samples are obtained after sintering at $1200 \mathrm{C}$ when zirconia is alloyed with $12 \mathrm{~mol} \%$ $\mathrm{CeO}_{2}$.

\subsection{Non-isothermal grain growth}

Non-isothermal grain growth data up to $1050 \mathrm{C}$ are listed in Table 2, whereas additional grain growth data for ZY5 (the grain growth in the Y,Ce-TZP 
Table 6. Relative densities and percentages of the tetragonal phase of Ce-TZP sintered isothermally at various temperatures

\begin{tabular}{cccccc}
\hline Sample & $\begin{array}{c}\text { Temperature } \\
\left({ }^{\circ} \mathrm{C}\right)\end{array}$ & $\begin{array}{c}\text { Time } \\
(\mathrm{h})\end{array}$ & $\begin{array}{c}\rho_{\text {rel }} \\
(\%)\end{array}$ & $\begin{array}{c}\text { Grain size } \\
(\mu \mathrm{m})\end{array}$ & $\begin{array}{c}\text { Tetragonal } \\
(\%)\end{array}$ \\
\hline ZCe6.8 & 1030 & 15 & 92 & & 87 \\
& 1030 & 30 & 94 & 0.095 & 40 \\
& 1060 & 10 & 95 & & 32 \\
& 1110 & 3 & 95 & 0.14 & 20 \\
ZCe9 & 1220 & 30 & 94 & $1 \cdot 0$ & 4 \\
& 1060 & 30 & 89 & 0.15 & 92 \\
& 1110 & 10 & 96 & $\sim 0.2$ & $\sim 99$ \\
ZCe12 & 1110 & 30 & 93 & 0.35 & 84 \\
& 1190 & 5 & 94 & 0.59 & 32 \\
& 1200 & 2 & 97 & 0.18 & $\sim 99$ \\
\hline
\end{tabular}

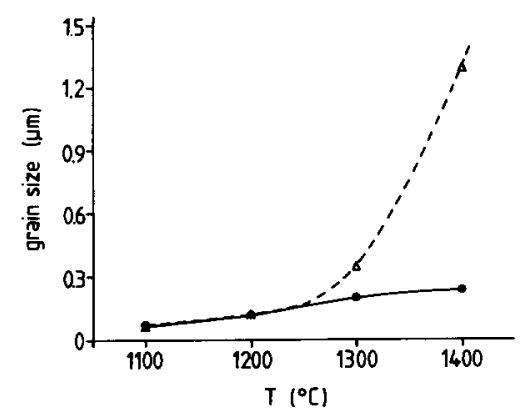

Fig. 7. Non-isothermal grain size evolution in (--) ZY5 and $\left(--\triangle^{--)} \mathrm{ZCe} 9\right.$ sintered with a heating rate of $2^{\circ} \mathrm{C} / \mathrm{min}$.

compacts is comparable) and $\mathrm{ZCe} 9$ samples are given in Fig. 7 up to $1400^{\circ} \mathrm{C}$. Combining Table 2 and Fig. 7 it can be seen that below $1200^{\circ} \mathrm{C}$ the grain growth behaviour of all compacts is identical, although the grain growth rate in the ceriacontaining compacts is slightly slower at low temperature. This behaviour was somewhat surprising because, as shown in Ref. 8, an impurity drag mechanism could be expected in the Y-TZP samples while this was not expected for the Ce-TZP samples (no significant segregation of cerium to the grain boundaries at these low temperatures, see also Table 3). Obviously the intrinsic grain growth rate in the Ce-TZP samples is low. This can be understood by considering the slowest diffusing species in both materials (i.e. $\mathrm{Ce}^{3+} / \mathrm{Ce}^{4+}$ in Ce-TZP and $\mathrm{Y}^{3+}$ in $\mathrm{Y}$ TZP). The ionic radii of $\mathrm{Y}^{3+}$ and $\mathrm{Ce}^{4+}$ are comparable $\left(1.015\right.$ and $\left.0.97 \AA^{25}\right)$, but $\mathrm{Ce}^{4+}$ has a higher electric charge. Therefore the tetravalent cerium species will be bound more strongly to the anion lattice and thus the diffusion coefficient is expected to be lower. Due to the larger ionic radius ${ }^{25}$ of $\mathrm{Ce}^{3+}$ this species is also expected to have a smaller diffusion coefficient that $\mathrm{Y}^{3+}$. This means that the relatively slow intrinsic grain growth in Ce-TZP is probably a matter of slower diffusion kinetics of the $\mathrm{Ce}$ species. Apparently this kinetic effect has a comparable effect in Ce-TZP to the (not yet fully developed) dragging force in Y-TZP. ${ }^{8.21}$

Above $1200^{\circ} \mathrm{C}$ grain growth in Ce-TZP accelerates and is much faster than in Y-TZP (Fig. 7). As shown in Ref. 21, a full segregation profile has developed in the Y-TZP samples at about $1100^{\circ} \mathrm{C}$, which gives an effective dragging force for grain growth control. In sample ZCe9 significant segregation is not yet present at $1300^{\circ} \mathrm{C}$ despite the considerable fraction of trivalent cerium (Table 3 ). At this temperature the mobility of trivalent and tetravalent cerium ions becomes sufficient to result in an increased grain growth. At $1400^{\circ} \mathrm{C}$ significant segregation of cerium takes place. Effective grain growth control in fine-grained Ce-TZP ceramics can only be obtained when significant segregation is present at a stage where the grains are still rather small. As indicated before, the grain growth behaviour of the $Y, T_{i}-T Z P$ and, $Y, C e-T Z P$ samples resembles the grain growth behaviour of Y-TZP (Table 7). The slightly larger grains might be attributed to the observation that the grain boundaries are less enriched in yttrium, ${ }^{21}$ which probably

Table 7. Grain sizes (in $\mu \mathrm{m}$ ) of doped zirconia materials after isothermal sintering at $1400^{\circ} \mathrm{C}$ (all samples are nearly 100\% tetragonal, except for the Ce-TZP samples)

\begin{tabular}{ccccccc}
\hline Time $(h)$ & ZY5 & ZY4Ce2 & ZY4Ce4 & ZCe6.8 & ZCe9 & ZY5Ti5 \\
\hline 0 & 0.24 & 0.39 & 0.43 & & 1.3 & 0.42 \\
2 & 0.30 & 0.51 & 0.50 & 7 & 1.9 & $0.60^{a}$
\end{tabular}

${ }^{a}$ With a few anomalous grains. 
results in a less effective grain growth retardation by means of the impurity drag mechanism.

\subsection{Isothermal grain growth}

Grain sizes of samples sintered isothermally at $1400^{\circ} \mathrm{C}$ are listed in Table 7. The grain sizes in the ternary systems are comparable with each other but larger than the grain size of the Y-TZP sample. On the other hand, the Ce-TZP materials have much larger grain sizes compared with Y-TZP and Y,CeTZP ceramics with a comparable total dopant concentration. Notable is the large grain size in a ZCe6. 8 sample after $2 \mathrm{~h}$ sintering $\left(\right.$ at $\left.1400^{\circ} \mathrm{C}\right)$. Duh et $a l^{26}$ showed that the grain size decreases when CeTZP is doped with yttrium. For instance, the grain size decreased from $1.9 \mu \mathrm{m}$ in a ZCe12 sample to $0 \cdot 9 \mu \mathrm{m}$ in a ZY2Ce 10 sample after $10 \mathrm{~h}$ sintering at $1400^{\circ} \mathrm{C}$. In another paper ${ }^{27}$ Duh et al. studied the influence of other dopants $(\mathrm{Mg}, \mathrm{Sm}, \mathrm{Nd}$, Dy) in the Ce-TZP system. In all cases a grain size of about $1 \mu \mathrm{m}$ was obtained after doping ZCe12 with $2 \mathrm{~mol} \%$ $\mathrm{MgO}, \mathrm{SmO}_{1.5}, \mathrm{NdO}_{1.5}$ and $\mathrm{DyO}_{1.5}(10 \mathrm{~h}$ sintering at $1400^{\circ} \mathrm{C}$. Ce-TZP had a grain size of $2 \mu \mathrm{m}$ after the same treatment. Probably their effect is similar to yttrium. Because the grain growth behaviour of the ternary systems is comparable to the grain growth behaviour of the Y-TZP materials (the grain growth is probably also controlled by means of an impurity drag mechanism) attention will be focused on the Ce-TZP compositions.

An isothermal grain growth curve of a ZCe6.8 sample sintered at $1110^{\circ} \mathrm{C}$ is shown in Fig. 8. For comparison three data points of a $\mathrm{ZCe} 9$ sample are added. The initial grain size at $t=0 \mathrm{~h}$ is $75 \mathrm{~nm}$ for both compositions. After $30 \mathrm{~h}$ sintering the grain size of $\mathrm{ZCe} 9$ is only slightly smaller than that of ZCe6.8. This indicates that at this temperature grain growth for these samples occurs with the same mechanism. The grain growth seems to be slow in the first $20 \mathrm{~h}$, after which the grain growth rate increases somewhat.

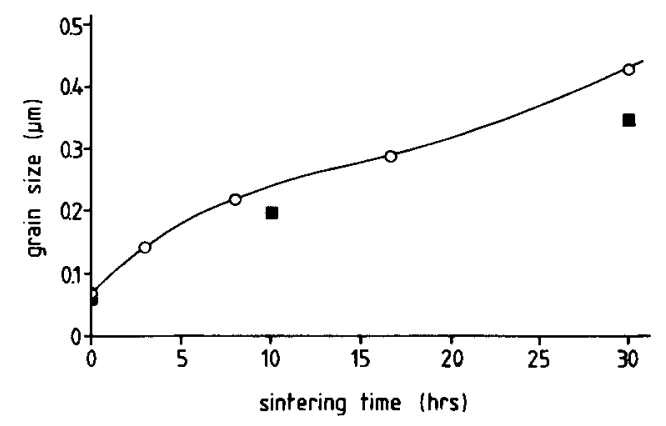

Fig. 8. Grain size evolution in $(-\mathrm{O}-\mathrm{ZCe} 6 \cdot 8$ and $(\boldsymbol{\square}) \mathrm{ZCe} 9$ sintered isothermally at $1110^{\circ} \mathrm{C}$.
A general grain growth equation has been developed by Brook: ${ }^{28}$

$$
G^{n}-G_{0}^{n}=k t
$$

with $G$ and $G_{0}$ the instantaneous and initial grain size, respectively, $k$ a kinetic constant, $t$ the time and $n$ a constant characteristic for the grain growth mechanism. When plotting the left-hand side term versus the time $(t)$ linear regression by the leastsquares method is used to determine the value of $n$.

When leaving out the last data point $(30 \mathrm{~h}) n=1$ yielded the lowest regression coefficient, but the other regression coefficients $(n=2-4)$ were not significantly different (for ZCe6.8). A value of $n=3$ (pointing to an impurity drag mechanism) is not very likely because of the absence of a segregation layer at this temperature. ${ }^{21} \mathrm{~A}$ value $n=4$ (pore drag control) is possible because a porosity of about $5-10 \%$ is continuously present. Considering the grain size evolution, a value of $n=2$ (normal grain growth) seems to be more likely.

If the final data point $(30 \mathrm{~h})$ is also taken into account the best fits are clearly obtained for $n=1$ and $n=2$. Due to the clear acceleration in grain growth rate a value $n=1$ (anomalous grain growth) seems to be more likely. This means that after a certain time of sintering the mechanism changes from normal to anomalous grain growth. At $1200^{\circ} \mathrm{C}$ (Fig. 9) the grain growth of ZCe9 seems to be clearly anomalous. Indeed some anomalous grains were found in the SEM pictures.

A similar grain growth picture as for $\mathrm{ZCe} 9$ at $1110 \mathrm{C}$ was obtained for a ZCe12 compact sintered at $1200^{\circ} \mathrm{C}$ (Fig. 9). Also in this case the grain growth rate accelerates after a certain time. When leaving out the last data point $(20 \mathrm{~h})$ the best fits are clearly obtained for $n$ values of 3 and 4 . Because these samples have a density of more than $97 \%$ of the theoretical density pore-controlled grain growth $(n=4)$ seems not very likely. This points to a value of $n=3$ as the most likely grain growth constant. The

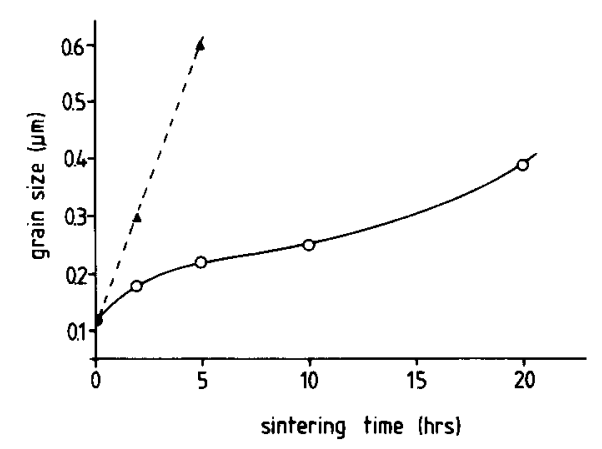

Fig. 9. Grain size evolution in (-- $\mathrm{ZCe}^{--}$and $(-\mathrm{O}-)$ ZCe12 sintered isothermally at $1200^{\circ} \mathrm{C}$. 
surface composition of these samples has not been investigated, so the occurrence of an impurity drag mechanism cannot be supported with any further experimental evidence. When also using the last data point, $n=1$ and 2 again provide the best fit. So also in this case the occurrence of anomalous grain growth is indicated and anomalous grains are indeed seen in the SEM pictures.

The difference in grain growth behaviour between $\mathrm{ZCe} 9$ and $\mathrm{ZCe} 12$ compacts might be attributed to the fact that the ZCe9 sample was mainly monoclinic whereas the ZCe12 sample remained fully tetragonal (Section 3.7).

\subsection{Retainment of the tetragonal phase}

Garvie \& Swain ${ }^{29}$ derived an equation in which the critical grain size $\left(d_{\mathrm{c}}\right)$ for transformation is described as a function of the $M_{\mathrm{s}}$ temperature:

$$
\frac{1}{d_{\mathrm{c}}}=C_{1}+C_{2} M_{\mathrm{s}}
$$

$C_{1}$ and $C_{2}$ are constants. The $M_{\mathrm{s}}$ temperature is a measure of the thermal stability. The thermal stability increases with decreasing $M_{\mathrm{s}}$. If $d<d_{\mathrm{c}}$ the tetragonal structure is retained at or above the $M_{\mathrm{s}}$ temperature. When measuring $M_{\mathrm{s}}$ temperatures it has to be ensured that only the grain size effect is measured. This implies similar densities (Section 2) and a similar degree of reduction for all samples. Since all samples are isothermally sintered between 1030 and $1200^{\circ} \mathrm{C}$ the fraction of trivalent cerium is believed to be small (Section 3.3) and comparable for all the samples within a certain composition.

The temperature dependence of $1 / d_{\mathrm{c}}$ is given in Figs 10 and 11 for ZCe6.8 and ZCe9 samples, respectively. From these figures the constants listed in Table 8 are derived. With a similar critical grain size it can be calculated that the $M_{\mathrm{s}}$ temperature in ZCe6.8 is much higher than that of ZCe9. With a critical grain size of $0.4 \mu \mathrm{m}$ the $M_{\mathrm{s}}$ temperatures are

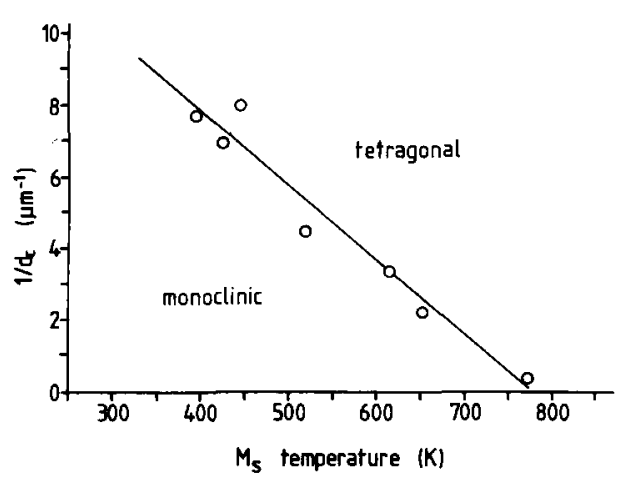

Fig. 10. Temperature dependence of the reciprocal critical grain size for the $\mathrm{t} \rightarrow \mathrm{m}$ transformation in $\mathrm{ZCe} 6.8$.

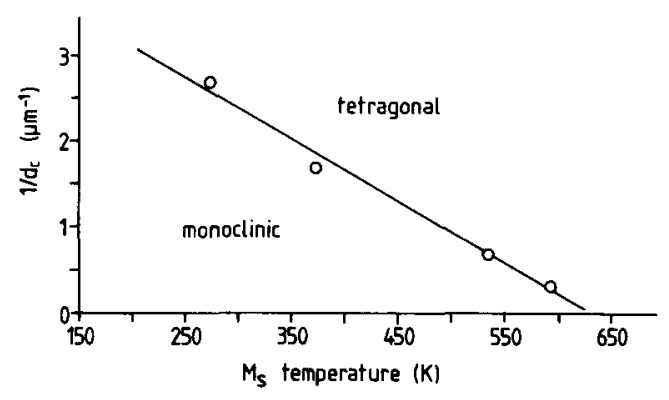

Fig. 11. Temperature dependence of the reciprocal critical grain size for the $\mathrm{t} \rightarrow \mathrm{m}$ transformation in $\mathrm{ZCe} 9$.

384 and $25^{\circ} \mathrm{C}$ for $\mathrm{ZCe} 6.8$ and $\mathrm{ZCe} 9$, respectively. Therefore it can be concluded that the thermal stability increases with increasing cerium content. It is important to know what the critical grain size is for retainment of the tetragonal phase at room temperature (i.e. $M_{\mathrm{s}}<20^{\circ} \mathrm{C}$ ). These critical grain sizes are listed in Table 8 . The critical grain size for ZCe6.8 $(0 \cdot 1 \mu \mathrm{m})$ is close to the critical grain size for $8.4 \mathrm{~mol} \% \mathrm{Ca}-\mathrm{PSZ}^{29}$ but the critical grain size of the ZCe9 sample is clearly larger $(0.4 \mu \mathrm{m})$. This suggests that $\mathrm{Ce}$ is a better stabilizer for the tetragonal phase than $\mathrm{Ca}$. With increasing ceria concentration the thermal stability becomes rather good. ZCe12 samples with an average grain size of $2.0 \mu \mathrm{m}$ are still fully tetragonal. Even after long-term ageing at 180 and $350^{\circ} \mathrm{C}$ in air no monoclinic phase was observed in ZCe12 with a grain size of $2.5 \mu \mathrm{m}^{4}$ Sato \& Shimada ${ }^{5}$ estimated a critical grain size of about $3 \mu \mathrm{m}$ for retainment of the tetragonal phase at room temperature.

The critical grain size for ZY5.8 at room temperature is about $0.8-1.0 \mu \mathrm{m} .{ }^{1.13,30}$ For $\mathrm{ZY} 4$ the critical grain size is about $0 \cdot 3 \mu \mathrm{m} .{ }^{30}$ Therefore it can be concluded that yttrium is a better stabilizer for the tetragonal phase than cerium calcium.

Khan et $a l .{ }^{31}$ showed that after alloying ZY4 with cerium the thermal stability clearly increased. With a grain size of $1 \cdot 2 \mu \mathrm{m}$ (for $\mathrm{ZY} 4 \mathrm{Ce} 2$ ) the structure was still fully tetragonal. The same was shown by Sato et $a l .{ }^{13}$ This suggests that the combination of $\mathrm{Y}$ and $\mathrm{Ce}$ is more effective than each of the individual components at the same concentration. It can be expected that the thermal stability will increase even more with increasing $\mathrm{Y}$ or $\mathrm{Ce}$ concentration.

Table 8. Values of constants $\left(C_{1}, C_{2}\right)$ in eqn (6) and critical grain sizes $\left(d_{\mathrm{c}}\right)$ corresponding to $M_{\mathrm{s}}=293 \mathrm{~K}$

\begin{tabular}{lccc}
\hline \multicolumn{1}{c}{ Sample } & $\begin{array}{c}C_{1} \\
\left(m^{-1}\right)\end{array}$ & $\begin{array}{c}C_{2} \\
\left(m^{-1} K^{-1}\right)\end{array}$ & $\begin{array}{c}d_{\mathrm{c}} \\
(\mu m)\end{array}$ \\
\hline ZCe6.8 & $1.63 \times 10^{7}$ & $-2.10 \times 10^{4}$ & 0.1 \\
ZCe9 & $4.57 \times 10^{6}$ & $-7.23 \times 10^{3}$ & 0.4 \\
Ca-PSZ ${ }^{29}$ & $1.64 \times 10^{7}$ & $-1.83 \times 10^{4}$ & 0.09 \\
\hline
\end{tabular}


Furthermore, Sato et al. ${ }^{13}$ reported a fully tetragonal phase in the ZY6Ti5 system with a grain size of $5.1 \mu \mathrm{m}$. This leads to the conclusion that the thermal stabilities of the ternary materials used in this study are quite good. Although titanium in itself may be very effective as a stabilizer usually no dense ceramics are obtained in the Ti-TZP system.

Bastide et al $^{32}$ studied the relation between $1 / d_{\mathrm{c}}$ and the $M_{\mathrm{s}}$ temperature for the zirconia-lanthana system. There they found that eqn (6) was applicable when the lanthana content was higher than $6 \mathrm{~mol} \%$. However, the thermal stability was rather poor. For a zirconia sample alloyed with $9 \cdot 3 \mathrm{~mol} \% \mathrm{La}_{2} \mathrm{O}_{3}$ a grain size of $\sim 0.15 \mu \mathrm{m}$ is necessary to stabilize the tetragonal phase down to room temperature. In another paper, where zirconia was alloyed with $1 \mathrm{~mol} \% \mathrm{Y}_{2} \mathrm{O}_{3}$, Bastide et al. ${ }^{33}$ suggested that 6-7 mol\% $\mathrm{CeO}_{2}$ should be enough to stabilize the tetragonal phase to room temperature. Although no grain sizes were given this seems to support the present measurements.

The effect of the $M_{\mathrm{s}}$ temperature on the mechanical properties and the transformability under influence of an external stress is discussed in Ref. 21.

\subsection{Chemical stability}

Some results of the ageing experiments are shown in Table 9. It is clear that, even when very fine-grained, no completely chemically stable ZY4 can be obtained (small fractions of monoclinic phase are always found). With constant grain size the stability increases with yttria dopant concentration. However, above a certain grain size the stability is poor again (for instance shown in the ZY5.5 and ZY6.1 samples). For a ZY $5 \cdot 8$ sample this critical grain size

Table 9. Fraction monoclinic phase $\left(V_{\mathrm{m}}\right)$, calculated according to eqn (1), of the zirconia samples after an ageing treatment $(5 \mathrm{~h}$ at $180 \mathrm{C}$ in $\mathrm{H}_{2} \mathrm{O}$ ) (all samples were originally $>99 \%$ tetragonal)

\begin{tabular}{lll} 
Sample & \multicolumn{1}{c}{$V_{\mathrm{m}}$} & Grain size $(\mu \mathrm{m})$ \\
\hline ZY4 & $0.92^{a}$ & $0 \cdot 10$ \\
& $0 \cdot 97$ & $0 \cdot 15$ \\
ZY5.1 & $0 \cdot 96^{a}$ & $0 \cdot 20$ \\
ZY5.5 & 0.05 & $0 \cdot 18$ \\
& $0 \cdot 13^{a}$ & $0 \cdot 25$ \\
ZY6.1 & $0 \cdot 92^{a}$ & $0 \cdot 40$ \\
ZY6.5 & $\mathrm{t}$ & $0 \cdot 15$ \\
ZY4Ce2 & $0 \cdot 75^{a}$ & $0 \cdot 40$ \\
ZY4Ce4 & $\mathrm{t}^{a}$ & $0 \cdot 30$ \\
ZCe9 & $\mathrm{t}$ & $0 \cdot 15$ \\
& $\mathrm{t}$ & $0 \cdot 10$ \\
\hline
\end{tabular}

${ }^{a}$ After Winnubst \& Burggraaf. ${ }^{2}$

$\mathrm{t}=$ Only tetragonal phase detected.

Sample: $\left(\mathrm{ZrO}_{2}\right)_{100-x}\left(\mathrm{YO}_{1 \cdot 5}\right)_{x}$ denoted as $\mathrm{ZY} x$.
Table 10. XPS measurements on surfaces of aged ZY3Ti13 samples (conditions: $250^{\circ} \mathrm{C}$ in $\mathrm{H}_{2} \mathrm{O}$ at a pressure of $38 \mathrm{bar}$ )

\begin{tabular}{cccc}
$\begin{array}{c}\mathrm{ZrO} \\
(\mathrm{mol} \%)\end{array}$ & $\begin{array}{c}\mathrm{YO}_{1} \cdot 5 \\
(\mathrm{~mol} \%)\end{array}$ & $\begin{array}{c}\mathrm{TiO}_{2} \\
(\mathrm{~mol} \%)\end{array}$ & $\begin{array}{c}\text { Stability } \\
(\mathrm{h})\end{array}$ \\
\hline 83 & 7 & 10 & $<5$ \\
67 & 10 & 23 & $>500$ \\
\hline
\end{tabular}

was determined to be $0 \cdot 25^{2}$ and $0 \cdot 37 \mu \mathrm{m} .{ }^{34}$ Direct comparison of the present results with literature data is not possible because in the literature much coarser-grained materials are used in most cases.

Preliminary experiments on cerium-doped Y-TZP samples show an improved resistance against chemical ageing (Table 9), which is in agreement with the results of several authors. ${ }^{4,5.13,35}$ Therefore it can be concluded that small additions of cerium to the Y-TZP system improve the chemical stability.

In the past Sato et $a l^{13}$ showed that Y-TZP ceramics were chemically stable when they were alloyed with more than $10 \mathrm{~mol} \% \mathrm{TiO}_{2}$. In order to study the effect of $\mathrm{TiO}_{2}$ on the chemical stability, some ZY3Ti13 samples (gratefully received from Alusuisse-Lonza, Switzerland) and (ZY3Ti12 = $\left.\left(\mathrm{ZrO}_{2}\right)_{0.84}\left(\mathrm{YO}_{1.5}\right)_{0.03}\left(\mathrm{TiO}_{2}\right)_{0.13}\right)$ were aged. Some of the samples obtained aged very quickly, others showed a rather good resistance towards chemical attack (Table 10). XPS data obtained from the surfaces, together with chemical stability data, are listed in Table 10. It can be seen that the most stable sample is clearly surface-enriched in $\mathrm{Ti}$, whereas the unstable sample is not surface-enriched in Ti. Both samples are enriched in yttrium. The conclusion seems obvious that, just as in the Y.Ce-TZP samples with high $\mathrm{CeO}_{2}$ concentration, ${ }^{36}$ a large quantity of $\mathrm{TiO}_{2}$ on the grain boundaries might impede the attack on the active yttrium points. ${ }^{35}$ This might be due to the formation of a $\mathrm{TiO}_{2}$ overlayer. ${ }^{21}$

\section{Conclusions}

(1) The chloride synthesis yields ultrafine-grained, pure and highly reactive $\mathrm{Y}-\mathrm{Ce}$ - and Ti-doped zirconia powders.

(2) Y,Ce-TZP and Y-TZP powders show the same compaction behaviour. Although a similar picture was obtained for the Ce-TZP powders the agglomerates seem to be slightly weaker. In the compaction curve of the Y,Ti-TZP powder only one straight line was obtained, indicating the existence of very weak agglomerates.

(3) The existence of trivalent cerium in Ce-TZP could be demonstrated using (quantitative) 
TGA and (qualitative) IR measurements. The reduction reaction started significantly at about $1200^{\circ} \mathrm{C}$, but a slight reduction might occur at lower temperatures. The exact temperature depends on the porosity. In dense Ce-TZP (at $1400^{\circ} \mathrm{C}$ ) about $10 \%$ of the cerium was reduced.

(4) Y-TZP, Y,Ce-TZP and Y,Ti-TZP compacts densify in a similar way during non-isothermal sintering. Although the densification rate in the Ce-TZP compacts is faster, no dense samples could be obtained in the samples with low cerium concentration. This is attributed to fast grain growth at higher temperatures.

(5) Dense Ce-TZP (ZCe6.8 and ZCe9) could be obtained while sintering isothermally at relatively low temperatures for long times. In most cases, however, this was not accompanied by retainment of the tetragonal phase.

(6) Up to about $1200^{\circ} \mathrm{C}$ the non-isothermal grain growth behaviour was comparable for all the compacts studied. Between 1000 and $1200^{\circ} \mathrm{C}$ the grain growth in Y-containing samples was retarded by a developing impurity drag force caused by segregation of yttrium to the grain boundaries. The intrinsic grain growth in $\mathrm{Ce}-$ TZP is relatively slow, due to the slow kinetics of the diffusing species $\mathrm{Ce}^{3+} / \mathrm{Ce}^{4+}$ compared to $\mathrm{Y}^{3+}$. At higher temperatures the grain growth in Ce-TZP is fast, due to the absence of an effective grain growth retarding mechanism. In Y,CeTZP the grain growth is retarded by means of an impurity drag mechanism, although the grain growth rate is faster compared to that in Y-TZP.

(7) During isothermal sintering experiments the grain growth in Y,Ce-TZP and Y,Ti-TZP was comparable to that in Y-TZP, although slightly larger grain sizes were obtained. Doping Ce-TZP with yttrium effectively decreased the grain size. The grain growth in Ce-TZP was normal initially but became anomalous after about $15-$ $20 \mathrm{~h}$ sintering at 1110 and $1200^{\circ} \mathrm{C}$.

(8) Doping Y-TZP with cerium improves the chemical stability. In Y,Ti-TZP chemical attack might be prevented by formation of a titania 'overcoat layer'.

(9) The critical grain size for retainment of the tetragonal phase at room temperature $\left(M_{\mathrm{s}}<\right.$ $20^{\circ} \mathrm{C}$ ) is about 0.1 and $0.4 \mu \mathrm{m}$ for ZCe6.8 and $\mathrm{ZCe} 9$, respectively. A critical grain size $>2 \mu \mathrm{m}$ is estimated for ZCe12. The critical grain size in Y,Ce-TZP and Y,Ti-TZP is larger than in Y-TZP and Ce-TZP with the same total dopant concentration.

\section{Acknowledgements}

Dr H. Verweij and W. H. M. Bruggink (Philips Research Laboratories) are thanked for performing the TGA measurements. This research was partly supported by the Innovative Research Program on Technical Ceramics (IOP-TK) with financial aid of the Dutch Ministry of Economic Affairs.

\section{References}

1. Claussen, N., In Science and Technology of Zirconia II, ed. N. Claussen, M. Rühle \& A. H. Heuer. The American Ceramic Society, Inc., Columbus, Ohio, 1984, pp. 325-351.

2. Winnubst, A. J. A. \& Burggraaf, A. J., The aging behavior of ultrafine-grained Y-TZP in hot water. In Advances in Ceramics, Vol. 24A: Science and Technology of Zirconia III, ed. S. Somiya, N. Yamamoto \& H. Yanagida. The American Ceramic Society, Inc., Columbus, Ohio, 1988, pp. 39-47.

3. Sato, T. \& Shimada, M., Transformation of yttria-doped tetragonal $\mathrm{ZrO}_{2}$ polycrystals by annealing in water. $J . \mathrm{Am}$. Ceram. Soc., 68 (1985) 356-9.

4. Tsukuma, K., Mechanical properties and thermal stability of $\mathrm{CeO}_{2}$ containing tetragonal zirconia polycrystals. Am. Ceram. Soc. Bull., 65 (1986) 1386-9.

5. Sato, T. \& Shimada, M., Transformation of ceria-doped tetragonal zirconia polycrystals by annealing in water. $\mathrm{Am}$. Ceram. Soc. Bull., 64 (1985) 1382-4.

6. Reyes-Morel, P. E. \& Chen, I-W., Transformation plasticity of $\mathrm{CeO}_{2}$-stabilized tetragonal zirconia polycrystals. I: Stress assistance and autocatalysis. J. Am. Ceram. Soc., 71 (1988) 343-53.

7. Theunissen, G. S. A. M., Winnubst, A. J. A. \& Burggraaf, A. J., Sintering kinetics and microstructure development of nanoscale Y-ZTP ceramics. J. Eur. Ceram. Soc., submitted.

8. Winnubst, A. J. A., Theunissen, G. S. A. M., Groot Zevert, W. F. M. \& Burggraaf, A. J., The sintering behaviour of finegrained $\mathrm{ZrO}_{2}-\mathrm{Y}_{2} \mathrm{O}_{3}$ ceramics, In Science of Ceramics 14, ed. D. Taylor, The Institute of Ceramics, Shelton, Stoke-onTrent, UK, 1988, pp. 309-14.

9. Wakai, F. \& Nagono, T., The role of interface-controlled diffusion creep on superplasticity on yttria-stabilized tetragonal $\mathrm{ZrO}_{2}$ polycrystals. J. Mater. Sci. Lett., 64 (1988) $607-9$.

10. Burggraaf, A. J., Theunissen, G. S. A. M. \& Winnubst, A. J. A., Synthesis and properties of nanoscale ceramics and composites. In Euro-Ceramics, Vol.l: Processing of Ceramics, ed. G. de With, R. A. Terpstra \& R. Metselaar. Elsevier Science Publishers, London, 1989, pp. 8-12.

11. Leach, C. A., Development of the secondary tetragonal phase in conventionally sintered yttria-TZP ceramics. $J$. Mater. Sci. Lett., 6 (1987) 303-4

12. Lange, F. F., Marshall, D. B. \& Porter, J. R., Controlling microstructures through phase partitioning from metastable precursors: the $\mathrm{ZrO}_{2}-\mathrm{Y}_{2} \mathrm{O}_{3}$ system. In Ultrastructure Processing of Advanced Ceramics, ed. J. D. MacKenzie \& D. R. Ulrich. Wiley \& Sons, New York, 1988, pp. 519-32.

13. Sato, T., Ohtaki, S., Endo, T. \& Shimada, M., Improvement of thermal stability of yttria-doped tetragonal zirconia polycrystals by alloying with various oxides. Int. J. High Technology Ceramics, 2 (1986) 167-77.

14. Duh, J-G., Dai, H-T. \& Hsu, W-Y., Synthesis and sintering behaviour of $\mathrm{CeO}_{2}-\mathrm{ZrO}_{2}$ ceramics. J. Mater. Sci., 23 (1988) $2786-91$.

15. Heussner, K-H. \& Claussen, N., Strengthening of ceria- 
doped tetragonal zirconia polycrystals by reductioninduced phase transformation. J. Am. Ceram. Soc., 72 (1989) 1044-6.

16. Hernandez, M. T., Jurado, J. R. \& Duran, P., Processing, characterization and sintering behaviour of $\mathrm{Y}_{2} \mathrm{O}_{3}-\mathrm{TZP}$ and $\mathrm{Y}_{2} \mathrm{O}_{3}-\mathrm{TZP}-\mathrm{CeO}_{2}$ ceramics. In Materials Science Monographs 66. Ceramics Toda1-Tomorrow's Ceramics, ed. P. Vincenzini, Elsevier Science Publishers B.V., Amsterdam. 1991, pp. 1395-1404.

17. Groot Zevert, W. F. M., Winnubst, A. J. A., Theunissen, G.S.A.M. \& Burggraaf, A.J., Powder preparation and compaction behaviour of fine-grained Y-TZP. J. Mater. Sci., 25 (1990) 3449-55.

18. Verweij, H. \& Bruggink, W. H. M., Precision determination of the stoichiometry parameter $x$ of $\mathrm{YBa}_{2} \mathrm{Cu}_{3} \mathrm{O} . J$. Phis. Chem. Solids, 49 (1988) 1063-9.

19. Toraya, H., Yoshimura, M. \& Somiya, S., Calibration curve for quantitative analysis of the monoclinic-tetragonal $\mathrm{ZrO}_{2}$ system by X-ray diffraction. J. Am. Ceram. Soc., 67 (1984) C$119-\mathrm{C}-121$.

20. Oel, H. J., Bestimmung der grossenverteilung von teilchen, kristalliten und poren. Ber. Dtsch. Keram. Ges., 43 (1966) 624-31.

21. Theunissen, G. S. A. M.. Microstructure, fracture toughness and strength of (ultra)fine-grained tetragonal zirconia ceramics. PhD thesis, University of Twente, Enschede, The Netherlands, 1991.

22. Boutz, M. M. R., Theunissen, G. S. A. M., Winnubsı, A. J. A. \& Burggraaf. A. J., Grain growth during sintering of nanocrystalline $\mathrm{Y}$ - and/or Ce-doped tetragonal zirconia. In Materials Research Society Simposium Proceedings, Vol. 196: Superplasticity in Metals, Ceramics and Intermetallics, cd. M. J. Mayo, J. Wadsworth, M. Kobayashi \& A. K. Mukherjec. MRS, Pittsburgh. PA, 1990, pp. 87-92.

23. Mcriani, S., Features of the caeria-zirconia system. Mater. Sci. Eng.. A109 (1989) 121-30.

24. Phillipi, C. M. \& Mazdiyasni, K. S., Infrared and raman spectra of zirconia polymorphs. J. Am. Ceram. Soc, 54 (1971) 254-8

25. Shannon, R. D., Revised effective ionic radii and systematic studies of interatomic distances in halides and chalcogenides. Acta Cryst. A32 (1976) 75167.
26. Duh, J-G., Dai, H-T. \& Chiou, B-S., Sintering, microstructure, hardness, and fracture toughness behavior of $\mathrm{Y}_{2} \mathrm{O}_{3}-\mathrm{CeO}_{2}-\mathrm{ZrO}_{2}$. J. Am. Ceram. Soc., 71 (1988) 813-19.

27. Duh, J-G., Hsu, W-Y, \& Chiou, B-S., Study on rare-earthoxide-doped yttria tetragonal zirconia. In High Tech Ceramics, ed. P. Vincenzini. Elsevier Science Publishers BV, Amsterdam, 1987, pp. 1281-8.

28. Brook, R. J., Controlled grain growth. In Treatise of Materials Science and Technologl, Vol.9, ed. F. F. Y. Wang. Academic Press, New York, 1976, pp. 331-64.

29. Garvie, R. C. \& Swain, M. V., Thermodynamics of the tetragonal to monoclinic phase transformation in constrained zirconia microcrystals. Part 1: In the absence of an applied stress field. J. Mater. Sci.. 20 (1985) 1193200.

30. Lange, F. F. Transformation toughening: Part 3 Experimental observations in the $\mathrm{ZrO}_{2}-\mathrm{Y}_{2} \mathrm{O}_{3}$ system, $J$. Mater. Sci., 17 (1982) 240-6.

31. Khan, N., Leach, C. A. \& Stecle, B. C. H., Influence of microstructure on the electrical and mechanical behaviour of selected compositions in the $\mathrm{Zr}-\mathrm{Ce}-\mathrm{Y}-\mathrm{O}$ system. In EuroCeramics, Vol. 2: Properties of Ceramics, ed. G. de With, R. A. Terpstra \& R. Metselaar. Elsevier Science Publishers. London, 1989. pp. 241-5.

32. Bastide. B., Odier, P. \& Coutures, J. P.. Phase equilibrium and martensitic transformation in lanthana-doped zirconia. J. Am. Ceram. Soc.. 71 (1988) 449-53.

33. Bastide, B.. Canale, P. \& Odier, P., Characterization of a new ternary Ce Y tetragonal zirconia. J. Eur. Ceram. Soc., 5 (1989) 289-93.

34. Chen, S-Y. \& Lu, H-Y., Low-temperature ageing map for $3 \mathrm{~mol}^{\%} \% \mathrm{Y}_{2} \mathrm{O}_{3}-\mathrm{ZrO}_{2}$. J. Mater. Sci.. 24 (1989) 453-6.

35. Hernandez, M. T., Jurado, J. R., Duran, P. \& Garcia-Ficrro, J. L.. XPS studies to clucidate the ageing behaviour of $\mathrm{Y}_{2} \mathrm{O}_{3}-\mathrm{TZP}$ and $\mathrm{Y}_{2} \mathrm{O}_{3}-\mathrm{TZP}-\mathrm{CeO}_{2}$ ceramics. In Materials Science Monographs 66. Ceramics Today-Tomorrow's Ceramics, ed. P. Vincenzini, Elsevier Science Publishers B.V., Amsterdam, 1991, pp. 649-57.

36. Sato, T., Ohtaki, S., Endo, T. \& Shimada, M., Improvement of thermal stability of yttria-doped tetragonal zirconia polycrystals by doping $\mathrm{CeO}_{2}$ on the surface. J. Mater. Sc $i$. lett. 5 (1986) 1140-2. 